\title{
COMMUNICATION PROTOCOLS FOR COLLABORATIVE FORECASTING
}

\author{
Chin-Yin Huang \\ Department of Industrial Engineering and Enterprise Information \\ Tunghai University, Taichung, TAIWAN, huangcy@thu.edu.tw \\ Wu-Lin Chen \\ Department of Computer Science and Information Management, \\ Providence University, Taichung, TAIWAN, wlchen@pu.edu.tw
}

Jhih-Ming Chen

Department of Industrial Engineering and Enterprise Information

Tunghai University, Taichung, TAIWAN, farmer1003@hotmail.com

\begin{abstract}
In this research, protocols for activities of collaborative forecasting among the partnered companies are developed in accordance of twelve scenarios derived by market types (excess supply or excess demand), types of focal company (retailer, manufacturer, or material supplier), and type of integration (integrated or disintegrated). Each of the twelve scenarios has its specific protocol in modified sequence diagram. Additionally, eleven protocol modules are developed for constructing the twelve protocols. With the protocol modules, the protocols are presented in a more structural format and are more readable. A prototype system in Java program is also developed to illustrate the applicability of the protocols. By deploying the system over internet, the twelve protocols are realized and can regulate the communications of collaborative forecasting.
\end{abstract}

\section{INTRODUCTION}

Shorter product life cycle and uncertain market demands have forced today's companies not to choose a strategy of vertical integration, but to collaborate with other companies. The collaborative companies can flexibly and adaptively grasp transient opportunities by sharing the investments in human, machine, and facility resources (Abreu and Camarinha-Matos, 2008). However, as the size of a collaborative manufacturing network becomes large, bullwhip effect will significantly reduce the advantages of the network because the participating members are unable to economically meet the demand orders due to excessive or inadequate inventories. Fortunately, Lee and Whang (Lee and Whang, 2000) point out that though bullwhip effect is inevitable, collaborative forecasting could eliminate the disadvantageous effect.

Although some of systems have been defined to provide a platform for collaborative forecasting, e.g., VMI, CPFR, and Rosettanet, little research points out 
two critical concerns. First, companies in a collaborative manufacturing network are independent and autonomous. Although the focal company in a supply network is influential in a supply network, participating companies can still have their own freedom to cooperate with companies that does not belong to the same network. Second, because participating companies may not want to share completed information for collaboration, they may partially interchange erroneous or inflated information with each other (Cachon and Lariviere, 2001). As such, it results in a failure in the collaboration.

Applying simple protocols to coordinate the message interchanges among collaborative companies have been suggested as an effective approach for collaborative manufacturing (Chen, et al., 2008, Huang, et al., 2008a, Huang, et al., 2008b). However, the applications have been limited in production planning. Demand forecasting, as a key element that drives the collaborative manufacturing activities, is rarely investigated because of at least two reasons. First, usually demand forecasting is performed by the focal company in a supply network. Second, diverse market characteristics increase a difficulty to develop standardized protocols for companies.

This research intends to develop communication protocols for collaborative forecasting. The protocols define canonical interactive behaviors among companies, so efficient collaboration can be achieved. Additionally, the protocols are developed based on a peer-to-peer perspective. Therefore, the forecasting activities are not dominated by the focal company. Because only limited information that is defined in the protocols is shared in the activities of collaborative forecasting, participating companies can still hold their autonomy and privacy.

\section{LITERATURE REVIEW}

\subsection{Information sharing in supply chain}

Information sharing is a critical issue in supply chain. Due to complicated structures and constraints of supply chains, benefits of information sharing can only be limited in given conditions. It still lakes a comprehensive model for optimizing the design of information sharing in supply chain (Huang, et al., 2003). Xu et al. (Xu, et al., 2001) point out that one-forecast policy is a key to success of supply chain collaboration. According to their idea the one-forecast policy is made by either the retailer or the manufacturer. Actually communication protocols would provide a synthesizing mechanism for integrating multiple forecasts made by the participating companies (or supply chain entities). More specifically, not every participating company can receive benefit from information sharing. Zhao and Xie (Zhao and Xie, 2002) use simulation to explain that despite the retailers share forecast information (e.g., projected net requirement), their costs, including order processing costs, transportation costs, and inventory carrying costs, actually increase. Only the manufacturers receive substantial large cost savings. Additionally, the demand pattern significantly affects how forecasting errors influence the value of information sharing (Zhao and Xie, 2002). Literature indicates that the design of production information sharing is actually under a lot of design considerations of supply chain. How to share information so the participating companies can receive benefits and hold their autonomy is still a research issue. 


\subsection{Design concerns of collaborative forecasting}

Sauer (Sauer, 2006) points out that performing production planning with distributed processes has the following concerns:

1. Interdependencies between companies

2. Integration of local companies' production plans

3. Necessity to co-ordinate with other companies' production plans

4. Uncertainties happening in each local company.

Similar concerns could also occur in collaborative forecasting. By revising the above concerns, design concerns of collaborative forecasting are as follows:

1. Interdependent forecast on demands and supplies between participating companies.

2. Integration of multiple interdependent forecasts

3. Necessity to coordinate with other companies' forecasts

4. Uncertainties happening in each participating company.

\subsection{Communication protocols for information sharing}

Huang et al. (Huang, et al., 2008a) propose the concept to apply communication protocols for interchanging order information. Their approach reduces the costs and risks of full sharing information among the participating companies. Applying rules of communication (protocols) for integrating collaborative activities has been proposed in various articles as a feasible and important direction in collaborative manufacturing (Hammami, et al., 2003, Neubert, et al., 2004, Nof, et al., 2006). Chen et al. (Chen, et al., 2008) applied communication protocols for multi-tier and multi-site production planning of TFT-LCD manufacturing. However, to the authors' best knowledge, there is still no research investigating how to integrate demand forecast activities across collaborative manufacturing companies.

\subsection{Supply and demand in the market}

Many unexpected costs (e.g., late shipments, unhappy customers, too much inventory, lengthy lead time, and excess manufacturing costs) could occur when demand and supply are not balanced at the volume and the mix levels (Wallace and Stahl, 2002). In a supply network, the demand information is forecasted by the downstream company, whereas the supply information is forecasted by the upstream company. It becomes more complex when the forecasting activities are performed by companies along multiple tiers of a supply chain. Excess demand or excess supply in the market largely affects the activities of collaborative forecasting. Hence, both market types (excess demand and excess supply) will be a classifier when we design the scenarios of collaborative forecasting.

\section{COLLABORATIVE FORECASTING FRAMEWORK}

\subsection{Scenarios of collaborative forecasting}

Variation of forecasting is associated with three factors: market type, type of focal 
company, and type of integration. Market type is about the balance of demand and supply of the product. There are three kinds of market types: balanced, excess demand, and excess supply. This research focuses only on excess demand and excess supply. Lambert and Cooper (Lambert and Cooper, 2000) specify the existence of a focal company in a supply chain (network). A focal company is the most influential company in a collaborative network. It is of three types (a retailer, a manufacturer, or a supplier). However, an influential focal company may not be powerful enough to obtain detailed forecasting information from the other participating companies, unless the focal company can control the other participating companies by acquisition or some other marketing strategies. The third factor, type of integration, is to explain such a condition. If the other companies are controllable, the type of integration is integrated. Otherwise, it is disintegrated.

Based on the three factors, twelve scenarios can be developed, as shown in Figure 1.

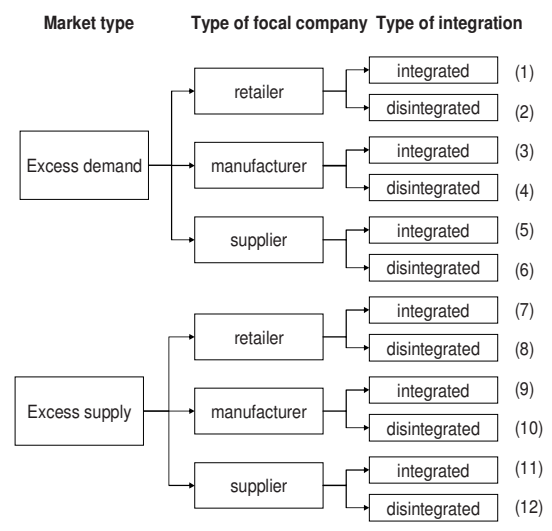

Figure 1 - Twelve scenarios of collaborative forecasting

\subsection{Protocol modules}

In order to correspond with the twelve scenarios, forecast-related production information is further classified into three types: general, expanded, and advanced. General type of production information is applied when only limited information is required for decision. For example, in a market of excess demand each company will only require sending an overall demand to its upstream companies. Expanded type of production information is applied when additional information is required. For example, in a market of excess supply an upstream company will require specific information regarding each product (e.g., due date, specifications, quantity, etc.), so inventory can be minimized. Advanced type of production information is applied when further sales and shipping plan are required for decision. This kind of production information is required when the companies are under high pressure of cost control in the operation. Table 1 shows the protocol modules that have been defined in this research in four categories. Each protocol module is defined by an icon for better visualization and a set of messages that will be applied in protocols. 
Table 1- Protocol modules for protocols of collaborative forecasting

\begin{tabular}{|c|c|c|c|c|}
\hline Category & $\begin{array}{l}\text { Protocol } \\
\text { module }\end{array}$ & Icon & Message & Direction \\
\hline \multirow{3}{*}{ Order } & $\begin{array}{l}\text { General } \\
\text { order } \\
\text { forecast }\end{array}$ & & $\begin{array}{l}\text { customer/order ID/ } \\
\text { product/overall demand } \\
\text { /inventory/due date }\end{array}$ & \multirow{3}{*}{$\begin{array}{c}\text { Upwards } \\
\text { (from retailer } \\
\text { to } \\
\text { manufacturer } \\
\text { or } \\
\text { from } \\
\text { manufacturer } \\
\text { to } \\
\text { Supplier) }\end{array}$} \\
\hline & $\begin{array}{l}\text { Expanded } \\
\text { order } \\
\text { forecast }\end{array}$ & & $\begin{array}{c}\text { customer/order ID/ } \\
\text { product/individual } \\
\text { demand/inventory/due } \\
\text { date }\end{array}$ & \\
\hline & $\begin{array}{l}\text { Advanced } \\
\text { order } \\
\text { forecast }\end{array}$ & & $\begin{array}{l}\text { customer/order ID/ } \\
\text { product/sales plan/ } \\
\text { individual demand/ } \\
\text { inventory/due date }\end{array}$ & \\
\hline \multirow{3}{*}{ Market } & $\begin{array}{c}\text { General } \\
\text { market } \\
\text { information }\end{array}$ & $\mathbf{J}$ & $\begin{array}{c}\text { customer/order ID/ } \\
\text { product/overall demand/ } \\
\text { new market information/ } \\
\text { inventory/due date }\end{array}$ & \multirow{3}{*}{$\begin{array}{c}\text { Upwards } \\
\text { (from retailer } \\
\text { to } \\
\text { manufacturer } \\
\text { or } \\
\text { from } \\
\text { manufacturer } \\
\text { to } \\
\text { Supplier) }\end{array}$} \\
\hline & $\begin{array}{l}\text { Expanded } \\
\text { market } \\
\text { information }\end{array}$ & $\mathcal{E}$ & $\begin{array}{c}\text { customer/order } \\
\text { ID/product/individual } \\
\text { demand/new market } \\
\text { information/inventory/due } \\
\text { date }\end{array}$ & \\
\hline & $\begin{array}{l}\text { Advanced } \\
\text { market } \\
\text { information }\end{array}$ & & $\begin{array}{c}\text { customer/order } \\
\text { ID/product/individual } \\
\text { demand/new market } \\
\text { information/sales plan/ } \\
\text { individual demand/new } \\
\text { market information/ } \\
\text { inventory/due date/ }\end{array}$ & \\
\hline \multirow{4}{*}{ Reply } & $\begin{array}{l}\text { General } \\
\text { order } \\
\text { acceptable }\end{array}$ & & $\begin{array}{l}\text { replier/order } \\
\text { ID/product/date }\end{array}$ & \multirow{4}{*}{$\begin{array}{l}\text { Downwards } \\
\text { (from } \\
\text { manufacturer } \\
\text { to } \\
\text { retailer } \\
\text { or } \\
\text { from supplier } \\
\text { to } \\
\text { manufacturer) }\end{array}$} \\
\hline & $\begin{array}{l}\text { Advanced } \\
\text { order } \\
\text { acceptable }\end{array}$ & & $\begin{array}{l}\text { replier/order ID/product/ } \\
\text { date/inventory/delivery } \\
\text { plan }\end{array}$ & \\
\hline & $\begin{array}{c}\text { General } \\
\text { partial order } \\
\text { acceptable }\end{array}$ & & $\begin{array}{l}\text { replier/order ID/product/ } \\
\text { date/promised quantity }\end{array}$ & \\
\hline & $\begin{array}{l}\text { Advanced } \\
\text { partial order } \\
\text { acceptable }\end{array}$ & & $\begin{array}{l}\text { replier/order ID/product/ } \\
\text { date/inventory/promised } \\
\text { quantity/delivery plan/ }\end{array}$ & \\
\hline Other & invitation & & $\begin{array}{c}\text { sender/ } \\
\text { "request for a forecast" }\end{array}$ & $\begin{array}{l}\text { Sender to } \\
\text { invitee }\end{array}$ \\
\hline
\end{tabular}

Each protocol module is specified by detailed message passing. Through the modified sequence diagram (Odell, et al., 2000), each protocol module is defined as the example in Figure 2. Figure 2 shows protocol module of general order forecast. 
It is a simple protocol that sending general order forecast from the retailer to the manufacturer. After receiving the information, the manufacturer simply store the information and then feedback a success or failure message about receiving the forecast information back to the retailer. Due to space limit, the other ten protocol modules are not shown.

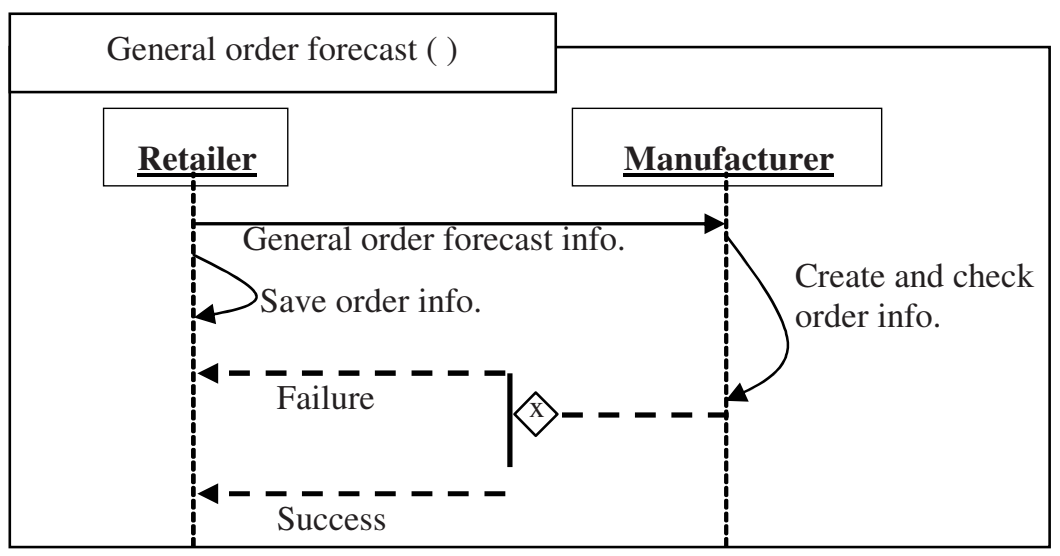

Figure 2 - Protocol module of general order forecast

\subsection{Protocols}

Due to the space limit of the article, only three scenarios (Nos. 1, 12, and 3 in Figure 1) and their corresponding protocols are introduced.

\section{Scenario No. 1}

Figure 3 shows a protocol that is applied for the following scenario. The scenario is separated into two phases: (1) regular forecast and (2) forecast update.

In the beginning of Phase (1), the retailer (focal company) sends a demand forecast to the manufacturers. Since the market type is excess demand, only simple information (products and overall demands) are required in the message transmission. When a manufacturer receives the forecast, it makes a plan for materials and capacity, so further inventory replenishment plan can be made. Based on the inventory replenishment plan, each manufacturer can send a demand forecast for the materials (including the forecast from the retailer) to the suppliers. When a supplier receives the forecasts from the downstream companies, it sends an acceptance message back. Due to the characteristics of excess demand, the supplier basically will try to meet the demand and apply the protocol module of general acceptable order to send back the acceptance information to the manufacturer. When a manufacturer receives the information from the supplier, it actives the advanced partial-acceptable order to give information to the retailer about the quantity of the products it can deliver. The retailer may inform some other associated manufacturers about its forecast. Therefore, further information is transmitted to the manufacturers accordingly.

However, market demand is fluctuating. Therefore, forecast should be updated. Phase (2) is applied to perform the update throughout the collaborative network. The 
major objective of Phase (2) is to provide a consistent forecast for the participating companies. Phase (2) starts when the retailer (focal company) creates an update on the forecast. The update affects the upstream companies. Hence, it has to be transmitted upwards for updating each participant's forecast. Further acknowledgements by protocol module general acceptable module are sent back to the retailer accordingly.

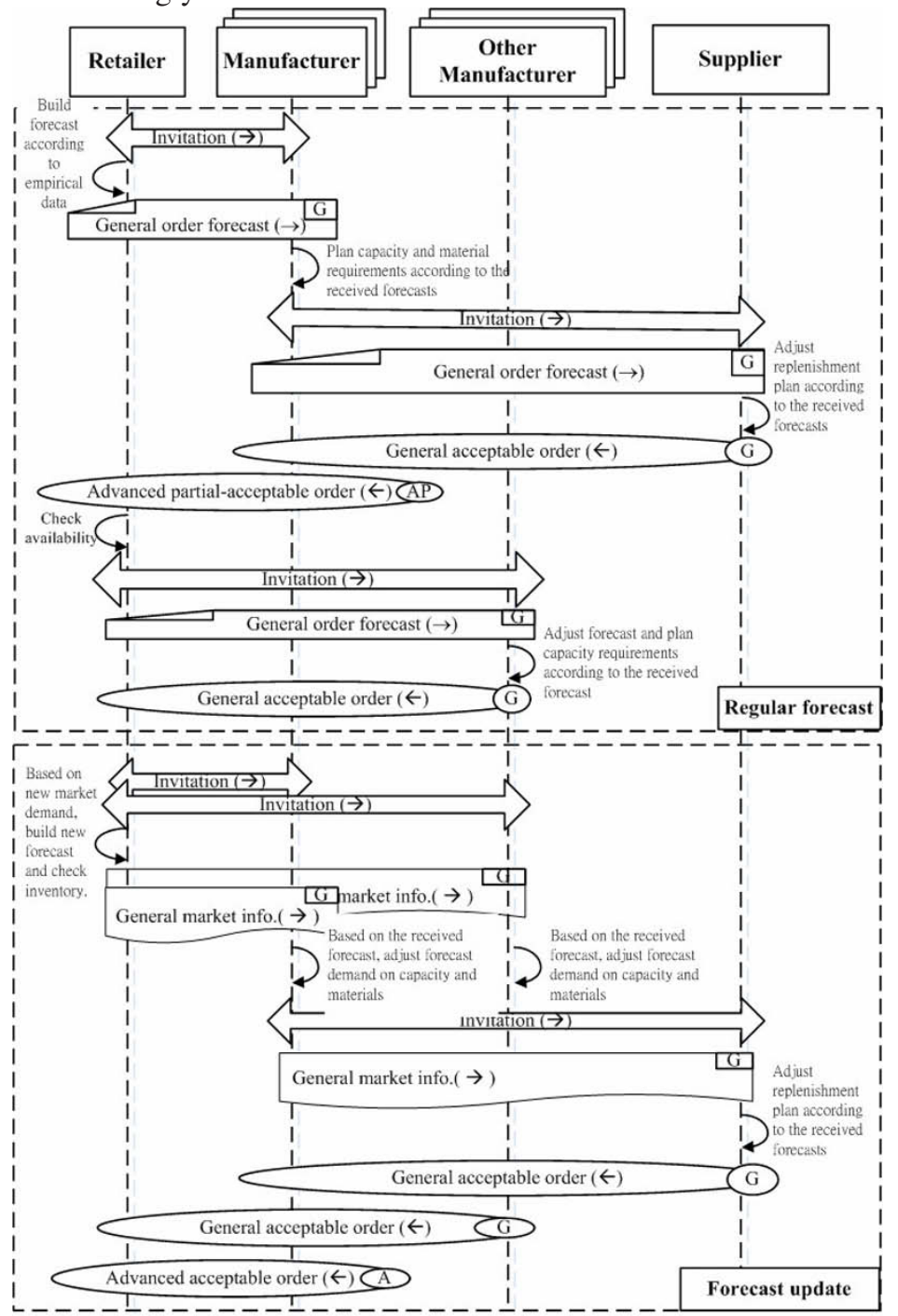

Figure 3 - Protocol for Scenario No. 1

\section{Scenario No. 12}

An opposite scenario (Scenario No. 12) to Scenario No. 1 is shown in Figure 4. In Phase (1) of the protocol, the supplier invites the downstream companies to participate in the forecasting. Then, the retailer gives the general order forecast to its neighboring upstream partner. Since the supplier is unable to integrate the 
downstream partners, the upstream partners (including the retailer) only need to apply general order forecast protocol module. Similarly, each participant sends general order forecast upwards. When the supplier receives the forecasts, it decides the replenishment plan and actuates general order accept protocol module to sends an agreement downwards to the participants. Phase (2) is similar to Phase (1) except that this portion of the protocol is activated by the retailer to adjust the forecast made in Phase (1).

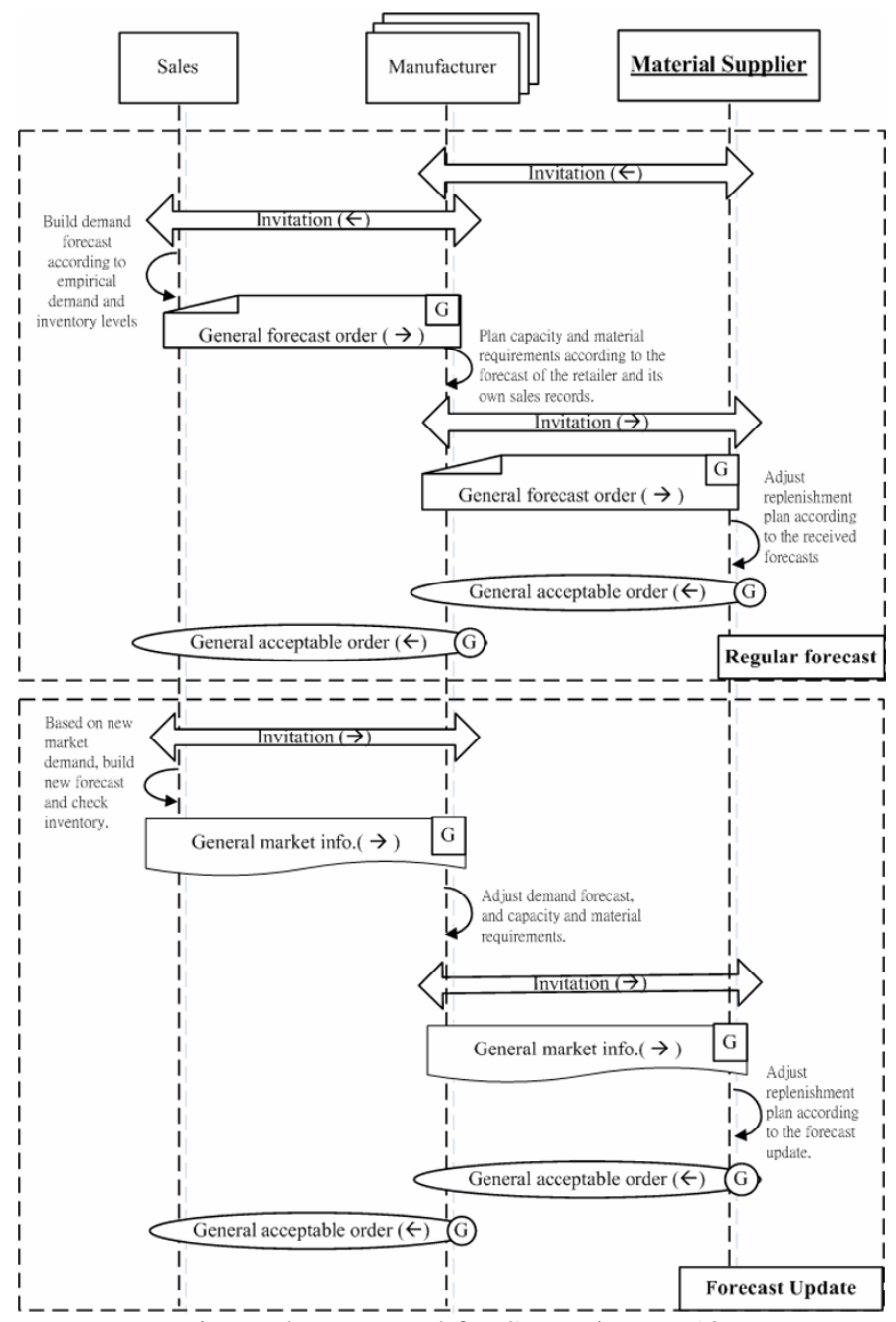

Figure 4 - Protocol for Scenario No. 12

Scenario No. 3

The third scenario (Scenario No. 3) in Figure 5 is about an excess demand market, within which the manufacturer is the focal company. The manufacturer is able to integrate the upstream and downstream partners. In this scenario, because the manufacturer can control other companies, the retailer activates an expanded order 
forecast protocol model in the beginning to deliver more detailed forecast information to the manufacturer. After receiving the forecast from the retailer, the manufacturer may proceed its forecasts based on its available capacity and materials in the inventories. Then, the forecasts are sent to its outsourcers (some other manufacturers) and suppliers. The outsourcers and suppliers can make their forecast accordingly and feedback their forecasts. It should be noted that the supplier should applied the advanced acceptable order protocol module to feedback detailed forecast, because the manufacturer is the integrated company. Similar interactions in Phase (2) will be proceeded when the retailer updates the forecasts according to the condition changes of the market.

\section{SYSTEM DEPLOYMENT}

This research deploys the protocols into a collaborative manufacturing network through internet, as shown in Figure 6. The collaborative manufacturing network consists of four participating companies: a retailer, two manufacturers, and a supplier. Each participant has two interfaces (developed by Java language), one for sending messages and one for receiving messages. Figure 7 shows an example of how a manufacturer interacts with its supplier. The left panel shows the manufacturer is expecting a demand of 200 units in day 23. It has 100 units in the inventory. By applying the general order forecast protocol module, it sends the forecast to the supplier. When the supplier receives the information, it agrees with the demand of 200 units. Then, it freezes the demand until day 20. It also has 100 units in the inventory. The information is entered into the right panel in Figure 7 and sends to the manufacturer by the protocol module of general acceptable module.

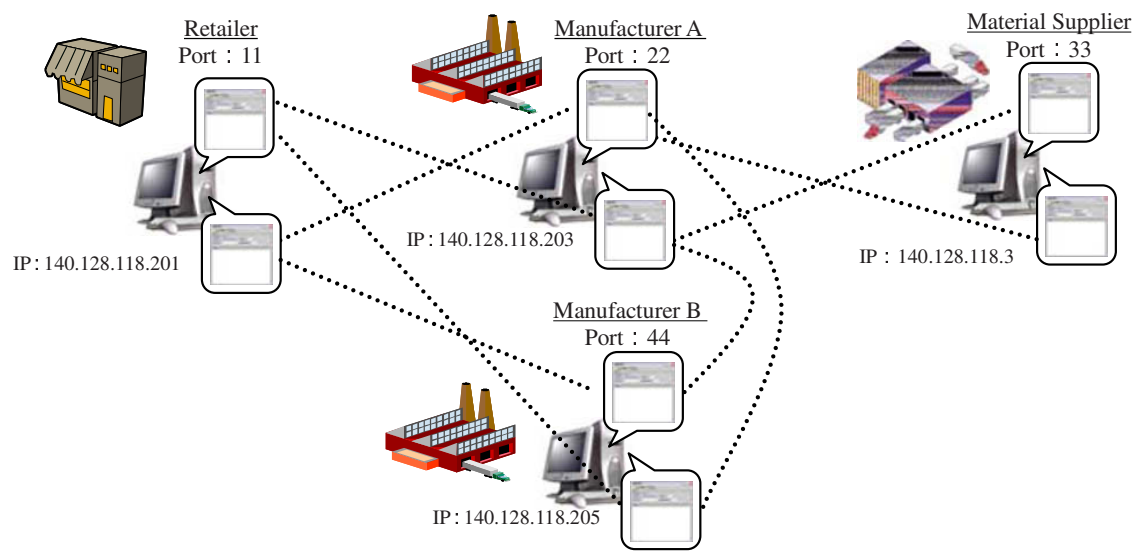

Figure 6 - Protocol deployment for four companies 


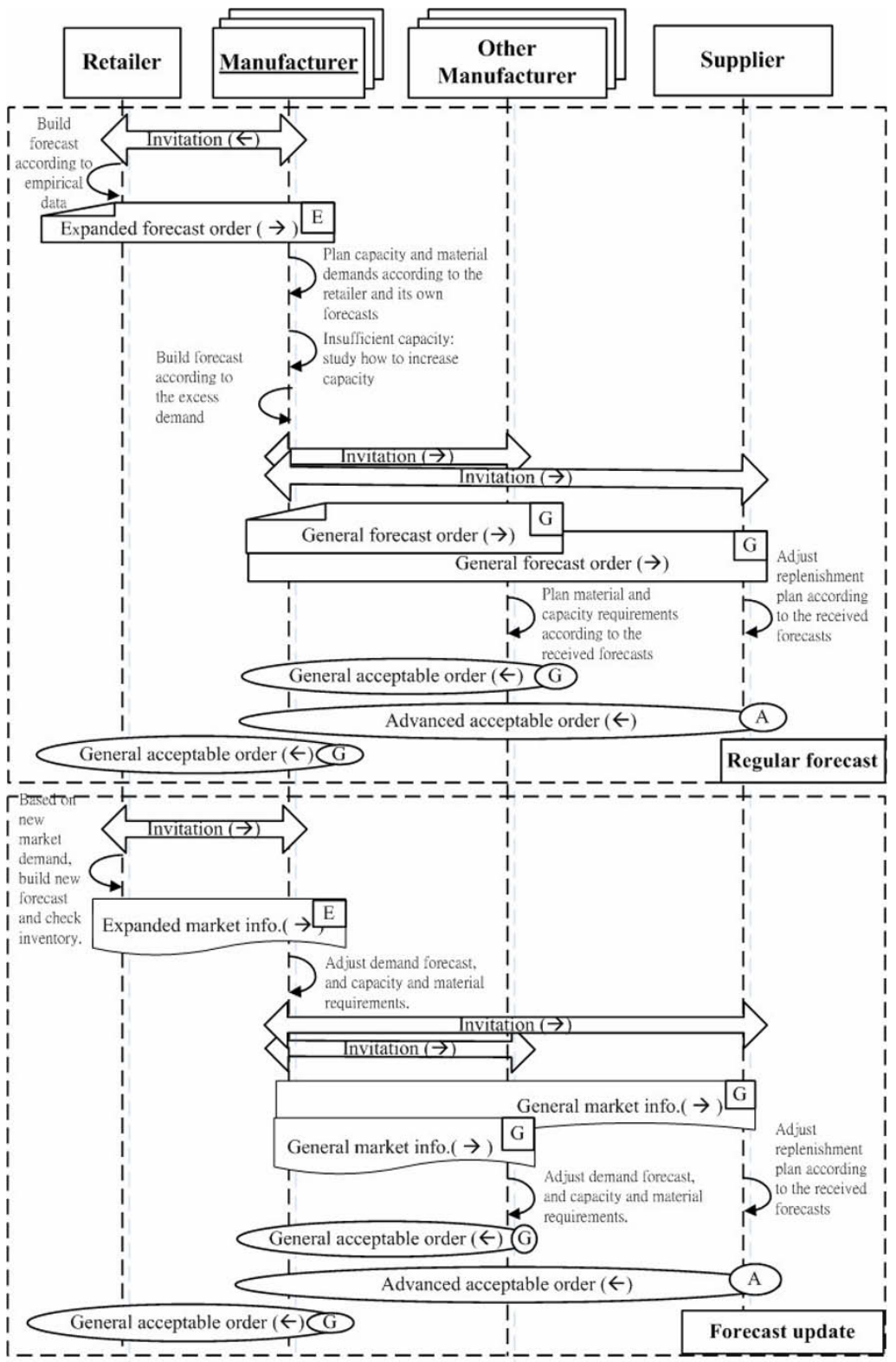

Figure 5 - Protocol for Scenario No. 3 

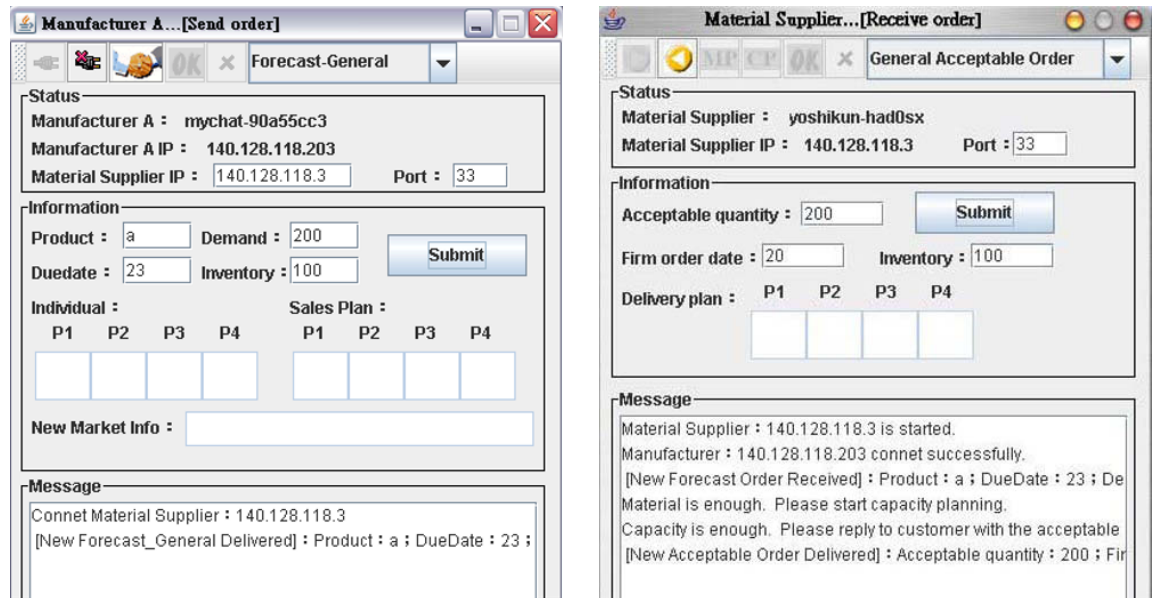

Figure 7 - Two illustrative interfaces (left: manufacturer; right: supplier)

\section{CONCLUSIONS AND FUTURE RESEARCH}

Information sharing among collaborative manufacturing companies is beneficial. However, to share forecast information is not easy for many reasons (autonomy and privacy of local companies, etc.). This research intends to provide communication protocols for collaborative forecasting. Only limited information is required to be shared with other partners for the collaboration. Hence, autonomy and willingness of collaboration for the participating companies will increase for collaborative forecasting. Twelve protocols are developed in accordance with the market type, type of focal company, and type of integration. An information system is also developed to deploy the protocols.

The future research based on this research could be (1) to realize the protocols in the real world applications and (2) to develop an evaluation model to justify the value of the protocols.

\section{ACKNOWLEDGEENTS}

The authors would like to thank the financial support from the research project NSC 95-2221-E-029-031, National Science Council, Taiwan.

\section{REFERENCES}

1. Abreu A, Camarinha-Matos LM. On the role of value systems to promote the sustainability of collaborative environments. International Journal of Production Research 2008; 46(5): 1207-29.

2. Cachon GP, Lariviere MA. Contracting to assure supply: How to share demand forecasts in a supply chain. Management Science 2001; 47(5): 629-46.

3. Chen WL, Huang CY, Lai YC. Multi-tier and multi-site collaborative production: Illustrated by a case example of TFT-LCD manufacturing. Computers \& Industrial Engineering 2008; To appear. 
4. Hammami A, Burlat P, Campagne JP. Evaluating orders allocation within networks of firms. International Journal of Production Economics 2003; 86(3): 233-49.

5. Huang CY, Huang CC, Liu CY. Order confirmation mechanism for collaborative production networks. International Journal of Production Research 2008a; 46(3): 595-620.

6. Huang CY, Huang TS, Chen WL. Communication Protocols for Order Management in Collaborative Manufacturing. International Journal of Production Economics 2008b; To appear.

7. Huang GQ, Lau JSK, Mak KL. The impacts of sharing production information on supply chain dynamics: a review of the literature. International Journal of Production Research 2003; 41(7): 1483517.

8. Lambert DM, Cooper MC. Issues in supply chain management. Industrial Marketing Management 2000; 29(1): 65-83.

9. Lee HL, Whang SJ. Information sharing in a supply chain. International Journal of Technology Management 2000; 20(3-4): 373-87.

10. Neubert R, Gorlitz O, Teich T. Automated negotiations of supply contracts for flexible production networks. International Journal of Production Economics 2004; 89(2): 175-87.

11. Nof SY, Morel G, Monostori L, Molina A, Filip F. From plant and logistics control to multienterprise collaboration. Annual Reviews in Control 2006; 30(1): 55-68.

12. Odell J, Parunak HVD, Bauer B. Extending UML for agents Proceedings of the 2nd Int. BiConference Workshop on Agent-Oriented Information Systems, AOIS'00 Austin (USA), 2000:3-17.

13. Sauer J. Modeling and solving multi-site scheduling problems. In: W. van Wezel, R.J. Jorna, Meystel AM, eds. Planning in Intelligent Systems: Aspects, Motivations and Methods Hoboken, NJ: John Wiley \& Sons, 2006:281-99.

14. Wallace TF, Stahl RA. Sales forecasting : a new approach : why and how to emphasize teamwork, not formulas, forecast less, not more, focus on process improvement, not forecast accuracy. Cincinnati, Ohio: T.F. Wallace \& Co., 2002.

15. Xu KF, Dong Y, Evers PT. Towards better coordination of the supply chain. Transportation Research Part E-Logistics and Transportation Review 2001; 37(1): 35-54.

16. Zhao XD, Xie JX. Forecasting errors and the value of information sharing in a supply chain. International Journal of Production Research 2002; 40(2): 311-35. 